\title{
BREEDINGTOMATO FOR EARLY BLIGHT RESISTANCE UNDER EGYPTIAN CONDITIONS \\ Ramadan W.A ${ }^{1}$ and A.A.Elkafrawy ${ }^{2}$ \\ 1- Horticulture Research Institute. Agricultural Research Center, (ARC), Giza, Egypt \\ 2- Plant Pathology Research Institute, Agricultural Research Center (ARC), Giza, Egypt
}

\begin{abstract}
Early blight (EB), caused by fungus Alternaria solani Sorauer, is a destructive disease of tomato (Lycopersicon esculentum Mill.) in Egypt and elsewhere. Sources of genetic resistance have been identified within tomato related wild species, so, the resistance wild accession TL00970 from the AVRDC was crossed with three susceptible varieties (Castle Rock, Super marmande, Floradad) to produce three crosses (TL00970x castle rock ,TL00970 x Super Marmande and TL00970xFloradad)

. The genitors, F1, F2, BC1 and BC2 of the three crosses were used to study the inheritance of resistance Alternaria solani and to estimate the genetic parameters associated with resistance. Mean analysis, the F1 hybrids had severity at the end of epidemic values intermediary between those for the parents susceptible and the parent's resistant genitors the values were closer to the parent's susceptible genitors indicates that dominance was predominant over susceptibility, and not for resistance. Also, Mean analysis resulted in a more importance of the genic effect due to dominance, also, both additive, dominance and Epistatic (aa,ad, dd) effects were involved in early blight resistance. The analysis of variance resulted in the estimated additive variance was more important than the variance due to dominance deviations. The estimates of heritability in broad and narrow sense were low, revealed the magnitude of the environmental factors on the total variation. The data revealed that early blight resistance was quantitatively controlled by more than one gene.
\end{abstract}

\section{INTRODUCTION}

Early blight (EB), caused by Alternaria solani (Ellis \& Martin) Jones \& Grout, is one of the most common and destructive diseases of tomato, Lycopersicon esculentum Mill, in areas of heavy dew, rainfall, and high relative humidity (Barksdale, 1971; Nash and Gardner. 1988). EB is also important in semiarid areas when nightly dew is sufficiently frequent to allow disease development (Rotem and Reichert 1964.).The early blight pathogen produces several toxins to infect tomato plants. Among these toxins alternatic acid and Solanapyrone induce necrotic symptoms with encircled chlorosis and these toxins enhance the pathogen infection and the development of necrotic symptoms of $A$. solani (Langsdorf et al., 1990). Early blight is a 3phased disease that can produce collar rot, leaf blight (early blight) and fruit rot. Collar rot has serious implications for tomato growers both as a disease and as a source of inoculum for an EB epidemic. The leaf blight phase, commonly referred to as early blight, is characterized by the formation of dark-colored spots that are necrotic in the center and result in a concentric ring pattern. As lesions expand and become more numerous, leaves are blighted and plants are gradually defoliated.

Defoliation, which reduces yield and fruit quality and contributes to significant crop loss, is the most important phase of the disease. The calyx 
and fruit tissues are also susceptible to the fungus when infected, they contribute to reduced fruit yield and quality. Control of early blight is difficult when high temperature and humidity conditions are prevalent: 3 to 5 year crop rotation, routine fungicide applications, and use of disease-free seedlings are able to control the fungal pathogen. Fungicide treatments are generally the most effective control measures; however, they are not only costly but also create problems on environment, human health in all areas of the world (Herriot et al., 1986).

Breeding for disease resistance requires efficient screening techniques, genetic resources for resistance, knowledge of genetic and physiological mechanisms underlying resistance, and appropriate breeding strategies to transfer resistance genes into improved genetic backgrounds. Compared with many other diseases of tomato, limited progress has been made to improve EB resistance of tomato cultivars. Major difficulties in the past breeding efforts have been with the screening of plants for resistance and transferring of resistance genes across genotypes (Martin and Hepperly 1987.)

No genetic source of EB resistance is known within the cultivated species of tomato (Martin and Hepperly, 1987; Foolad et al., 2000). However, resistant accessions have been identified within wild species of tomato, in particular the green-fruited species L. hirsutum Humb., and Bonpl. (Barksdale and Stoner, 1977; Martin and Hepperly, 1987; Nash and Gardner, 1988a; Maiero et al., 1989) and the red-fruited species L. pimpinellifolium (Jusl.) Mill. (Martin and Hepperly, 1987; Kalloo and Banerjee, 1993). Some resistant wild accessions have been utilized in traditional breeding programs and several breeding lines and cultivars with measurable levels of resistance have been developed (Barksdale and Stoner, 1977; Gardner, 1988; Nash and Gardner, 1988b).

Resistant cultivars are the most convenient way to control early blight disease. However, there are limited resistance sources available to produce strong resistant plants to the fungal pathogen because of quantitative expression and polygenic inheritance of the resistance (Thirthamallappa and Lohitaswa, 2000; Chaerani et al., 2007). Additionally, the early blight pathogen has complex physiological, morphological and ecological characters, allowing genetic variation in $A$. solani during infection process (Chaerani and Voorrips, 2007). Extensive genetic studies on the inheritance of early blight resistance revealed different resistance sources from wild tomato accessions such as Solanum habrochaites and S. pimpinellifolium resulted in the same conclusion that the resistance is a quantitative trait with recessive and partially dominant polygenes, conferring resistance with complicated epistatic effects (Thirthamallappa and Lohitaswa, 2000; Maiero et al., 1990).

EB resistance in tomato does not follow the gene-for-gene model of vertical qualitative resistance proposed by (Flor 1971). In contrast, it has been characterized as a complex quantitative trait, controlled by additive and non-additive interaction effects of multiple genes and highly influenced by environmental factors (Nash and Gardner, 1988b). The inheritance was reported as being quantitative and recessive in some lines (Barksdale and 
Stoner, 1977) but partially dominant, with epistasis involved, in others (Gardner, 1988; Martin and Hepperly, 1987; Nash and Gardner, 1988a). Early blight resistance in verities NCEBR2 and NCEBR4 was quantitatively controlled by more than one gene or quantitative trait locus under controlled glasshouse environment (Özer and Şerife,2011).The heritability of EB resistance has been reported to be low to moderate (Foolad and Lin, 2001; Foolad et al., 2002a; Nash and Gardner, 1988a). Furthermore, expression of EB is associated with physiological maturity and fruit load of the plant. Latematuring and/or low yielding plants appear resistant, while they may not possess genetic resistance. Such confounding factors together with the complex genetic nature of the resistance have contributed to the limited success in breeding for EB resistance using traditional approaches. Thus, new strategies are needed for the identification, validation and effective transfer of genes for EB resistance in tomato. Resistance has been characterized as horizontal, controlled by polygenes, and highly affected by environmental conditions (Barksdale and Stoner, 1977; Nash and Gardner 1988)

Hybrid means of early blight for area under the disease progress curve were not significantly different from respective mid parent values, indicating additive genetic control. Epistasis also was present (Maiero and Timothy1990). The resistance to early blight was conferred by recessive polygenes at both seedling and adult plant stages. This polygenic early blight resistance revealed the importance of additive and additive $x$ additive gene effect at seedling stage and magnitude of dominance and dominance $x$ dominance gene effects at adult plant stage (Thirthamallappa and Lohitaswa, 2000)

This study aims at studying the inheritance of tomato resistance to Alternaria solani and estimated the genetic parameters associated with early blight resistance in the crossing of $L$. esculentum and wild accessions. And investigate the possibility to incorporate new genes of wild accessions, with recessive alleles with some cultivars to obtained hybrid having both resistance and good performance.

\section{MATERIALS AND METHODS}

The genetic materials used in the present study, including three tomato varieties and one wild accession. The three varieties were diverse in the origin and the characters, all varieties were susceptible to early blight and belong to species Lycopersicon esculentum Mil. All varieties were selfpollinated two generations, these varieties were (1) Castle Rock (USA)is a large fruit size, growth habit is determinate and maturity is medium.(2) Super Marmande (France) and (3) Flora-dad (USA) are a large fruit size, growth habit is semi determinate and maturity is late.(4) An accession of the wild tomatoTL00970 belong to Lycopersicon Sp., original seeds were provided from the AVRDC (Asian Vegetable Research and Development Center), this accession is a resistant to early blight and bacterial speck, a small fruit size, growth habit is semi determinate and maturity is early. 
In November 2010, at El Mansoura Horticulture Research station the three cultivars (Castle Rock, Super Marmande and Flora-dad), and accession TL00970 were sown in seedling trays and at 45 days post-emergence the seedlings were transplanted in greenhouse and grown to flowering. At the flowering stage, accessionTL00970was used as pollen supplier for the three cultivars (Castle Rock, Super Marmande and Flora-dad) to obtain the F1 generations .In November 2011, the parents and F1 generations were sown in seedling trays to produce the F2 generations and backcrossed to their parents to produce $\mathrm{BC} 1$ and $\mathrm{BC} 2$ generations(2012).In addition, the crosses between the parents were done again in the same manner to increasing F1 seeds as well as the parents were self-pollinated in order to increasing seeds prenatal genotypes. In the first January 2013, seeds of all six populations were sown in seedling trays under green house at El Mansoura Horticulture Research station, and at 45 days post-emergence the seedlings $\left(15^{\text {th }}\right.$ February 2013) were transplanted to plastic pots of $30 \mathrm{~cm}$ diameter and $25 \mathrm{~cm}$ depth in greenhouse at El Mansoura Horticulture Research station. Throughout the evaluation of early blight severity among the populations under study, the temperatures ranged from $25^{\circ} \mathrm{C}$ to $30{ }^{\circ} \mathrm{C}$ and $\mathrm{Rh}$ from $90 \%$ to $100 \%$, which are considered adequate for the development of early blight (Somappa et al., 2013)

The experimental design was a Randomized Complete Block Design with three replications. Each replicate consisted of 16 plots, which included 4 parents, 3F1's, 3 F2, $3 \mathrm{Bc} 1$ and $3 \mathrm{Bc} 2$ generations. Plot size was two rows for each parent as well as $\mathrm{F} 1$ hybrids, three rows for each back cross and four rows for F2 generations. All recommended cultural practices for the crop were undertaken according to the instruction laid down by the Agriculture Egyptian Ministry

\section{Inoculum preparation.}

Inoculum suspensions of isolate Alternaria solani was prepared by cultivating this fungi in Petri-dishes containing PDA medium for 10 days at $28 \pm 0 \mathrm{C}$. Mycelial mats were harvested by sterile brush, washed for several times with sterilized distilled water and then blended with water for 3 minutes in a blender. The inoculum fragments were counted using a heamacytometer and the concentration of mycelial suspension of pathogen was adjusted to 107 fragments/ml (Shahin and Shepared, 1979).

\section{Pathogenicity test.}

Pathogenicity test of $A$. solani was carried out in the greenhouse of Elmansoura Agricultural Research Station, El-Dakahlia governorate, Horticultural Institute, A.R.C. At 60 days old, plants were sprayed with the tested inoculum of $A$. solani isolate (107 fragments $/ \mathrm{ml}$ ) using $30 \mathrm{ml}$ of inoculum of each plant using a hand atomizer. Tween-20 (0.1\%) was used as emulsifier to reduce the surface tension of the inocula. The inoculated plants were kept under polyethylene bags for $48 \mathrm{~h}$ to increase humidity and then (Bokshi et al., 2003; Pelletier and fry, 1989). Development of early blight symptoms were observed periodically. Early blight disease severity on tomato plant was assessed by using 0-5 scale as described by Mayee and Dater (1986). 
Table (1): Description of disease scale (0-5).

\begin{tabular}{|c|l|}
\hline Scale & Description \\
\hline 0 & No symptoms on the leaf. \\
\hline 1 & $\begin{array}{l}0-5 \text { percent leaf area infected and covered by spot, no spot on petiole } \\
\text { and branches. }\end{array}$ \\
\hline 2 & $\begin{array}{l}6-20 \text { percent leaf area infected and covered by spot, some spots on } \\
\text { petiole. }\end{array}$ \\
\hline 3 & $\begin{array}{l}21-40 \text { percent leaf area infected and covered by spot, spots also seen } \\
\text { on petiole, branches. }\end{array}$ \\
\hline 4 & $\begin{array}{l}41-70 \text { percent leaf area infected and covered by spot, spots also seen } \\
\text { on petiole, branches, stem. }\end{array}$ \\
\hline 5 & $\begin{array}{l}>71 \text { percent leaf area infected and covered by spot, spots also seen } \\
\text { on petiole, branches, stem, fruits. }\end{array}$ \\
\hline
\end{tabular}

Percent Disease Index (PDA) was calculated after 8 days of inoculation for each plant using the formula adopted by Wheeler (1969) as follow:

\section{disease scale) $\times 100$}

\section{Data collection}

To evaluate the disease severity of early blight, the whole plant leaves were submitted to screening. It was best to record readings independently without knowing the value given at the previous reading at each date,. The selection to the resistance to early blight was done based on the minimum values of severity at the end of epidemic .The tomato plants were inoculated in March 2013, 15 days after the transplantation of the plants, and evaluations carried out after 8 days of inoculation every three days, for 6 times, until the plants were 86 days old.

\section{Data analysis}

Three ratings were utilized in classification the resistance based on interval rang of the parents as (1) susceptible $71-100 \%$ severity; (2) moderate $31-70 \%$ and (3) resistant $0-30 \%$. (Elsayed et al., 2012). To obtain estimates of the genetic resistance parameters of severity was analyzed using the GENES program (Cruz, 2001). The analysis of means was obtained using the method of Mather and Jinks (1982) and the minimum number of genes that determine the character was estimated using the formula derived by Burton (1951): )$$
\mathbf{R}^{2}
$$

$\mathrm{N}=\overline{8 \sigma^{2} \mathrm{a}}$

Where $\sigma^{2} \mathrm{a}=$ additive variance and $\mathrm{R}=$ the total width of the ${ }^{\mathrm{F} 2}$ (value in F2 minus the smaller value in F2). 


\section{RESULTS AND DISCUSSION}

Severity at end of epidemic mean was 27.53 for resistant accession TL00970 and 85.06, 80.6 and 78.3 for the susceptible varieties Castle rock, Super Marmande and Floradad, respectively. Illustrate the (Table 2) differences between the resistant accession and the susceptible varieties genitors in terms of resistance to Alternaria solani. Alternaria solani severity values of the $F_{1}$ individuals showed mean values of severity at end of epidemic intermediary between those for the parents susceptible and the parents resistant and closer to the susceptible parents with mean of 77.7, 74.2 and 73.3 for TL00970x castle rock, TL00970x Supermarmande and TL00970XFloradad, respectively, of severity at end of epidemic (Table 2), however they have the same interval of susceptible parents. The mean performance of $F_{2}$ populations decreased compared to their $F 1$ generations, $\mathrm{BC} 1$ and BC2 generations were similar to the values for their genitors (Table 2). This result could be attributed to the effect of dominance toward the susceptibility. Similar finding was reported by Elsayed et al., (2012) and Thirthamallappa and Lohitaswa, (2000). The variances were obtained for each generation presented in table 2 .

Table (2): Estimates of the means and variances for the severity of early blight caused by Alternaria solani of crosses and their populations.

\begin{tabular}{|l|c|c|c|c|c|c|}
\hline Crosses & Generation & No.plants & Mean & Variance & $\mathbf{V}(\mathbf{m})$ & $\mathbf{1 / V}(\mathbf{m})$ \\
\hline TL00970x castle rock & $\mathrm{P}_{1}$ & 30 & 27.53 & 70.25 & 2.34 & 0.42 \\
\cline { 2 - 7 } & $\mathrm{P}_{2}$ & 30 & 85.06 & 81.17 & 2.71 & 0.37 \\
\cline { 2 - 7 } & $\mathrm{F}_{1}$ & 30 & 77.7 & 85.73 & 2.86 & 0.35 \\
\cline { 2 - 7 } & $\mathrm{F}_{2}$ & 60 & 70.2 & 213.17 & 3.55 & 0.28 \\
\cline { 2 - 7 } & $\mathrm{Bc}_{1}$ & 45 & 68.93 & 151.29 & 3.36 & 0.3 \\
\cline { 2 - 7 } & $\mathrm{Bc}_{2}$ & 45 & 83.84 & 157.27 & 3.49 & 0.29 \\
\hline TL00970xSupermarmand & $\mathrm{P}_{1}$ & 30 & 27.53 & 70.25 & 2.34 & 0.43 \\
\cline { 2 - 7 } & $\mathrm{P}_{2}$ & 30 & 80.6 & 97.42 & 3.24 & 0.31 \\
\cline { 2 - 7 } & $\mathrm{F}_{1}$ & 30 & 74.2 & 100.71 & 3.35 & 0.3 \\
\cline { 2 - 7 } & $\mathrm{F}_{2}$ & 60 & 73.36 & 222 & 3.67 & 0.27 \\
\cline { 2 - 7 } & $\mathrm{Bc}_{1}$ & 45 & 67.64 & 168.42 & 3.74 & 0.27 \\
\cline { 2 - 7 } & $\mathrm{Bc}_{2}$ & 45 & 79.96 & 183.95 & 4.09 & 0.24 \\
\hline TL00970xFloradad & $\mathrm{P}_{1}$ & 30 & 27.53 & 70.25 & 2.34 & 0.43 \\
\cline { 2 - 7 } & $\mathrm{P}_{2}$ & 30 & 78.3 & 104 & 3.47 & 0.29 \\
\cline { 2 - 7 } & $\mathrm{F}_{1}$ & 330 & 73.3 & 118.77 & 3.95 & 0.25 \\
\cline { 2 - 7 } & $\mathrm{F}_{2}$ & 60 & 72.06 & 226.03 & 3.77 & .027 \\
\cline { 2 - 7 } & $\mathrm{Bc}_{1}$ & 45 & 65.67 & 179.27 & 3.98 & 0.25 \\
\cline { 2 - 7 } & $\mathrm{Bc}_{2}$ & 45 & 82.69 & 171.26 & 3.81 & 0.26 \\
\hline
\end{tabular}

Regarding to analysis of means by using the method of Mather and Jinks (1982).To test for presence of epistasis, the A, B and C Scaling tests were applied for the crosses studied, the significance of any of the three tests indicate the presence of non-allelic interaction (epistasis) while, if the Scaling tests values are insignificantly differed from zero, the additive- dominance model is adequate to interpret gene effects. therefore the results of Scaling tests (A,B and C) for this trait are presented in table (3), Regarding this trait the values of scaling tests were significantly differed from zero in all three $F_{1}$ hybrids, indicating to the presence of non-allelic interaction 
Table(3): Scaling tests (A, B and C) and their standard error for the severity of early blight caused by Alternaria solani of the crosses studied.

\begin{tabular}{|l|c|c|c|}
\hline \multirow{2}{*}{$\begin{array}{l}\text { CROSSES } \\
\text { Parameters }\end{array}$} & $\begin{array}{c}|c| \\
\text { TL00970xCast } \\
\text { rock }\end{array}$ & TL00970xsupermaramande & TL00970xfloradad \\
\hline A & $34.16^{\star *}$ & $36.64^{* \star}$ & $31.34^{* *}$ \\
\hline S.D & 1.74 & 2.28 & 1.97 \\
\hline B & $-15.88^{\star *}$ & $9.84^{\star *}$ & $15.71^{* *}$ \\
\hline SD & 2.27 & 2.17 & 2.32 \\
\hline S & $-34.2^{\star *}$ & $38.93^{\star *}$ & $38.23^{\star *}$ \\
\hline SD & 4.56 & 4.91 & 4.73 \\
\hline
\end{tabular}

The gene effects using the population means of three crosses (TL00970x castle rock ,TL00970 x Super Marmande and TL00970xFloradad) for the severity of Alternaria solani are presented in table (4), the results showed that he estimates mid parent $(\mathrm{m})$, additive(a)and dominance gene effect (d) were significant, while, the dominance gene effect was more important than additive gene effect. In addition the three crosses showed significant of three epistatic interaction parameters (aa, ad ,dd) for the severity of Alternaria solani. These results emphasize that additive, dominance and Epistatic (aa,ad,dd) effects were involved in early blight resistance and agree with conclusions from previous studies (Nash and Gardner, 1988b; Meiero et al., 1990; Gardner, 1988; Martin and Hepperly, 1987; Nash and Gardner, 1988a).

Table(4): Type of gene action and stander error for the severity of early blight caused by Alternaria solani of the crosses studied.

\begin{tabular}{|c|c|c|c|c|c|c|}
\hline \begin{tabular}{|l|} 
Crosses \\
V.Six \\
par.
\end{tabular} & $\begin{array}{l}\text { TL00970xCast } \\
\text { rock }\end{array}$ & sd & $\begin{array}{c}\text { TL00970xsuper } \\
\text { maramande }\end{array}$ & sd & TL00970xfloradad & sd \\
\hline $\mathrm{m}$ & $59.17^{\star \star}$ & 1.13 & $73.37^{\star \star}$ & 1.21 & $72.07^{\star *}$ & 1.12 \\
\hline$a$ & $-5.91^{* *}$ & 1.40 & $-14.53^{* *}$ & 1.55 & $-18.76^{* \star}$ & 1.40 \\
\hline d & $75.79^{\star *}$ & 5.33 & $28.68^{\star \star}$ & 5.78 & $30.4^{\star \star}$ & 5.35 \\
\hline $\mathrm{aa}$ & $52.49^{* *}$ & 5.32 & $7.55^{\star *}$ & 5.77 & $8.81^{*}$ & 5.29 \\
\hline ad & $25.02^{\star *}$ & 1.42 & $13.4^{* *}$ & 1.56 & $7.82^{\star *}$ & 1.45 \\
\hline $\mathrm{dd}$ & $-70.77^{\star \star}$ & 7.25 & $-54.03^{\star \star}$ & 7.92 & $-55.86^{* *}$ & 7.3 \\
\hline
\end{tabular}

The estimates of additive variance, variance due to dominance deviation, mean dominance degree, broad and narrow senses heritability and the number of genes that control characters were calculated (Table 5). The estimated additive variance were 117.8, 91.63 and101.52, and higher than the variance due to dominance deviations 16.33, 40.9 and 26.81 and represented approximately $87.8 \%, 69.14 \%$ and $79.11 \%$ of the genotypic variance for TL00970x castle rock, TL00970x Supermarmande and 
TL00970 X Floradad, respectively. These results agree with the results obtained by Maiero and Timothy (1990).

The heritability in broad (Hb.s) was 62.92, 59.7 and $56.77 \%$ while, narrow sense (Hn.s) was $55.26,41.27$ and 44.92 of severity for TL00970x castle rock, TL00970x Super Marmande and TL00970 X Floradad, respectively, revealed the magnitude of the environmental factors on the total variation. Similar finding was reported by Foolad et al. (2002) that demonstrated the heritability of resistant to early blight ranged from 65 to $71 \%$. In addition, the low heritability could be attributed to that the resistance measures by the severity is highly affect by the environmental factors, escape and subjective evaluation (Foolad and Lin, 2001; Foolad et al., 2002a; Nash and Gardner, 1988a). The low heritability observed here that often associated with quantitative traits, that could be attributed to the large interference of the environment factors on the expression of the trait studied (Ramalho et al.1993).

Table (5): The genetic parameters for the severity of early blight caused by Alternaria solani of the crosses studied

\begin{tabular}{|l|c|c|c|}
\hline crosses & $\begin{array}{c}\text { TL00970xCast } \\
\text { rock }\end{array}$ & $\begin{array}{c}\text { TL00970xsuper } \\
\text { maramande }\end{array}$ & TL00970xfloradad \\
\hline parameters & Estimates \pm S.D & Estimates \pm S.D & Estimates \pm S.D \\
\hline Phenotypic variance & $213.18 \pm 38.60$ & $222 \pm 40.2$ & $226.03 \pm 40.93$ \\
\hline Environmental variance & $79.05 \pm 11.63$ & $89.47 \pm 13.27$ & $97.70 \pm 14.63$ \\
\hline Genotypic variance & $134.13 \pm 43.64$ & $132.53 \pm 45.06$ & $128.33 \pm 45.67$ \\
\hline Additive variance & $117.8 \pm 89.61$ & $91.63 \pm 95.75$ & $101.52 \pm 96.81$ \\
\hline Variance of the dominance deviation & $16.33 \pm 94.65$ & $40.90 \pm 90.25$ & $26.81 \pm 94.02$ \\
\hline Broad-sense heritability & $62.92 \pm 8.49$ & $59.70 \pm 8.48$ & $56.77 \pm 8.58$ \\
\hline Narrow - sense heritability & $55.26 \pm 34.45$ & $41.27 \pm 37.79$ & $44.92 \pm 36.91$ \\
\hline Heterosis & $38.01 \%$ & $37.24 \%$ & $38.52 \%$ \\
\hline Average degree of dominance* & 0.53 & 0.95 & 0.73 \\
\hline Maximum value in the F2 generation & 100 & 96.0 & 94.0 \\
\hline Minimum value in the F2 generation & 35 & 44.0 & 35.0 \\
\hline Number of genes (Based on variances) & 4.48 & 3.69 & 4.29 \\
\hline
\end{tabular}

${ }^{*}$ based on variances

Susceptibility to early blight showed heterosis, as witnessed by the fact that although the F1 hybrids had severity at the end of epidemic values intermediary between those for the parents susceptible and the parent's resistant genitors the values were closer to the parent's susceptible genitors (Table 2).Indicates that dominance was predominant for susceptibility, and not for resistance. As based on the variances the estimated degree of mean dominance was 0.53, 0.95and 0.73for TL00970x castle rock, TL00970x Supermarmande and TL00970X Floradad, respectively indicated a partially dominant genic action, and low importance of the genic effect due to dominance .(Thirthamallappa and Lohitaswa, 2000; Maiero et al., 1990). They concluded that the resistance is a quantitative trait with recessive and partially dominant polygenes, conferring resistance with complicated epistatic effects

The predominant genic effect appeared to be different when subjected to mean analysis or variance analysis. Mean analysis resulted in a more importance of the genic effect due to dominance (Tables 4 ), whereas the 
analysis of variance resulted in low important dominance deviations than additive variance (Table 5). The positive sign indicates that dominance was predominant over susceptibility, and not for resistance, that would be more interesting. The contrasting results of the analyses suggest the occurrence of dominance deviations in different directions. The discrepancies in the results calculated using means and variances can also be explained through the possibility of unbalance of linkages of genes in repulsion in F2 (Kearsey and Pooni, 1996).

The high error associated with the additive and dominance variance estimates $(117.8 \pm 89.61,91.63 \pm 95.75,101.52 \pm 96.81$ and $16.33 \pm 94.65$, $40.90 \pm 90.25,26.81 \pm 94.02$ ) may also explain this contrast between the data produced by mean and variance analysis (Table 5). Variances components can present low precision and in many cases the error exceeds the estimated mean. Because of the error which may be associated with additive and dominance variance estimates, it is probable that the degree of mean dominance is sometimes overestimated. Ramalho et al., (1993) and Cruz et al.,(2004) noted that variances, second order statistics, are more reliable for this type of analysis because means do not always represent reality since positive and negative results can nullify each other. In tomato, inheritance of resistance to other pathogens such as Ralstonia solanacearum, which causes bacterial wilt, and Colletrotichum coccodes, which causes anthracnose, is also quantitative with partial dominance of the alleles conditioned for a high AUDPC value (Stommel and Haynes, 1998; Neto et al., 2002).

According to current model, the minimum number of genes controlling resistance was 4.48, 3.69 and 4.2 genes for TL00970x castle rock, TL00970x Supermarmand and TL00970 X Floradad, (Table 5) respectively. Estimated by the Burton (1951) minimum effective factors calculated with F2 generation indicating that resistance to Alternaria solani in tomato follows a polygenic inheritance pattern, thus supporting previous research results (Özer and Şerife,2011; Thirthamallappa and Lohitaswa, 2000; Chaerani et al., 2007). They reported that early blight resistance was quantitatively controlled by more than one gene or quantitative trait.

In conclusion, this investigation revealed that, resistance to Alternaria solani in tomato was quantitatively with dominance was predominant over susceptibility, and not for resistance, and controlled by more than one gene. Mean analysis resulted in a more importance of the genic effect due to dominance and both additive, dominance and epistatic (aa, ad, dd) effects were involved in early blight resistance. The analysis of variance resulted in low important dominance deviations than additive variance, so, the estimated additive variance was more important than the variance due to dominance deviations. The estimates heritability in broad and narrow sense were low, revealed the magnitude of the environmental factors on the total variation

\section{REFERENCES}


Barksdale T. H. (1971). Field evaluation for tomato early blight resistance. Plant Dis. Rep. 55:807-809.

Barksdale T.H. and A.K. Stoner, (1977) .A study of the inheritance of tomato early blight. Plant Dis. Rep. 61:63-65.

Bokshi, A. I.; S. C. Morris and B. J. Deverall (2003). Effects of benzothiadiazole and acetylsalicylic acid on $\beta-1$, 3-glucanase activity and disease resistance in potato. Plant Pathology, 52: 22 - 27.

Burton G.W. (1951). Quantitative inheritance in pearl millet (Pennisetum glaucum). Agron. J. 43:409-417.

Chaerani R. and R.E. Voorrips (2007) .Tomato early blight (Alternaria solani): the pathogen, genetics, and breeding for resistance. J. Gen. Plant. Pathol. 72: 335-347

Chaerani R; R. Groenwold;P. Stam and R.E .Voorrips (2007). Assessment of early blight (Alternaria solani) resistance in tomato using a droplet inoculation method. J. Gen. Plant Pathol. 73: 96-103.

Cruz C.D. (2001). Gene's program: Windows version - Computer Application in genetics and statistics. Publisher UFV, Viçosa, $648 \mathrm{pp}$.

Cruz C.D; A.J. Regazzi and P.C.S. Carneiro (2004).ModelsBiometricsApplied to the Improvement Genetic.3rd edition. Editor UFV, Viçosa, $585 \mathrm{pp}$.

Elsayed A.Y.; D.J.H. Silva; P.C.S .Carneiro andE.S.G. Mizubuti (2012).The inheritance of late blight resistance derived from Solanum habrochaites.Crop Breeding and Applied Biotechnology, 12: 199-205.

Flor, H. (1971). Current status of the gene-for-gene concept. Ann. Rev. Phytopathol. 8:275- 296

Foolad M.R. and G.Y. Lin (2001). Heritability of early blight resistance in a Lycopersicon esculentum $\infty$ L. hirsutum cross estimated by correlation between parent and progeny. Plant Breed. 120:173-177.

Foolad M.R.;L. Zhang; A. Khan;D. Niño-Liu, and G.Y. Lin (2002b). Identification of QTLs for early blight (Alternaria solani) resistance in tomato using backcross populations of a Lycopersicon esculentum $\infty \mathrm{L}$. hirsutum cross. Theor. Appl. Genet. 104:945-958.

Foolad M.R.; N. Ntahimpera; B.J. Christ and G.Y. Lin (2000). Comparison between field, greenhouse, and detached-leaflet evaluations of tomato germplasm for early blight resistance. Plant Dis. 84:967-972.

Foolad M.R.; P. Subbiah; and G. Ghangas (2002a) .Parent-offspring correlation estimate of heritability for early blight resistance in tomato, Lycopersicon esculentum Mill. Euphytica 126:291-297.

Gardner, R.G. (1988). NC EBR-1 and NC EBR-2 early blight resistant tomato breeding lines. Hort.Science 23:779-781.

Herriot AB, Jr. FL. Haynes, and P.B. Shoemaker (1986) .The heritability of resistance to early blight in diploid potatoes (Solanum tuberosum subsp. Phureja and stenotonum). Am. Potato J. 63: 229-23

Kalloo, G. and M.K. Banerjee, (1993). Early blight resistance in Lycopersicon esculentum Mill. Transferredfrom L.pimpinellifolium (L.) and L. hirsutum f. glabratum Mull. Gartenbauwissenschaft 58:238-240.

Kearsey M.J and H.S Pooni (1996) .The Genetical Analysis of Quantitative Traits. $1^{\text {st }}$ edition. Chapman and Hall, London, $381 \mathrm{pp}$. 
Langsdorf G;N. Furuichi;N. Doke andS Nishimura (1990). Investigations of Alternaria solani infections: detection of alternaric acid and a susceptibility-inducing factor in the spore-germination fluid of $A$. solani. J. Phytopathol. 128: 271-282.

Maiero M; Ng. TJ and T.H. Barksdale (1989). Combining ability estimates for early blight resistance in tomato. Journal of the American Society for Horticultural Science 114: 118-121

Maiero M; Ng TJ,and T.H. Barksdale (1990). Inheritance of collar rots resistance in the tomato breeding lines C193 and NCEBR-2. Phytopathology, 80: 1365-1368

Maiero M. and J.Ng, Timothy. (1990). Genetic resistance to early blight in tomato breeding lines. Hort.Science 25 (3) 344-346

Martin F. W., and P. Hepperly, (1987) .Sources of resistance to early blight, Alternaria solani, and transfer to tomato, Lycopersicon esculentum. J. Agric. Univ. Puerto Rico 71:85-95.

Mather K. and J.L. Jinks (1982). Biometrical Genetics. Great Britin, Univ.Press 3rd .Ed. 396pp.

MayeeC. D. and V. V. Dater (1986). Phytopathometry Technical Bulletion-1. Marathwad Agricultural University, Parabhani, pp. 25.

Nash A. F. and R. G. Gardner ( 1988). Heritability of tomato early blight resistance de- rived from Lycopersicon hirsutum P.I. 126445. J. Am. Soc. Hortic. Sci. 113:264-268.

Nash, A.F. and R.G. Gardner (1988b). Tomato early blight resistance in a breeding line derived from Lycopersicon esculentum PI 126445. Plant Dis. 72:206-209

Nash A.F. and R.G. Gardner(1988a). Heritability of tomato early blight resistance derived from Lycopersicon hirsutum P.I. 126445. J. Am. Soc. Hort. Sci. 113:264-268.

Neto A.F.L; M.A Silveira; R.M Souza; S.R Nogueira and C.M.G André (2002). Inheritance of bacterial wilt resistance in tomato plants cropped in naturally infested soils of the state of Tocantins. Crop Breed Appl Biotech 2:25-32

Özer .C and T .Şerife (2011).Genetic analysis of resistance to early blight disease in tomato .African J. of Biot. Vol. 10(79), pp. 18071-18077

Pelletier J. R. and W. E. Fry (1989) Characterization of resistance to early blight in three potato cultivars: Incubation period, lesion expansion rate, and spore production. Phytopathology, 5: $511-517$.

Ramalho M.A.P; J.B. Santos and M.J.O Zimmermann (1993).Quantitative genetic in pollinated plants: Applications to Bean Breeding. UFG Editor, Goiania, $271 \mathrm{pp}$.

Rotem J. and I. Reichert (1964). Dewa principal moisture factor enabling early blight epidemics in a semi-arid region of Israel. Plant Dis. Rep. 48:211-215

Shahin E. A. and J. F. Shepared (1979). An efficient technique for inducing profuse sporulation of Alternaria species. Phytopathology, 69: 618 620. 
Somappa J.; K. Srivastava; B. K. Sarma; P.A.L. Chhattarand K. Ravindra (2013).

Studies on growth conditions of the Altrnaria leaf spot causing Alternaria Solani. The Bioscan, 8(1): $101-104$.

Stommel J.R. and K.G. Haynes (1998). Inheritance of resistance to anthracnose caused by Colletotrichum coccodesin tomato. J Am Hort Sci 123:832-836

ThirthamallappaH and H.C Lohitaswa (2000). Genetics of resistance to early blight (Alternaria solani Sorauer) in tomato (Lycepersicum esculantum L.). Euphytica, 113: 187-1932.

Wheeler B.E.J. (1969). An Introduction to Plant Diseases. John Wiley and Sons Lim., London, pp. 301.

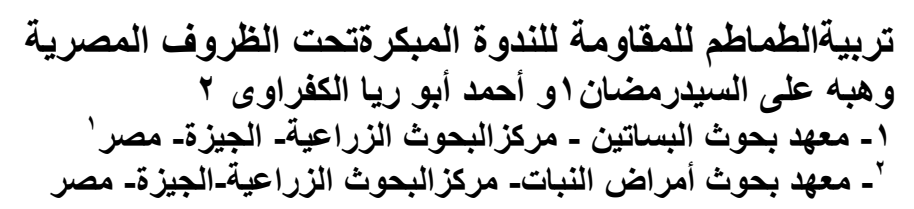

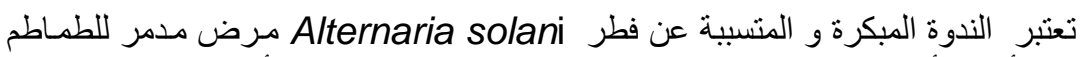

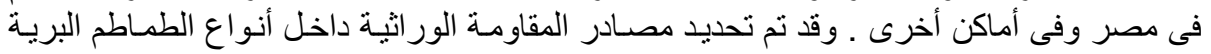

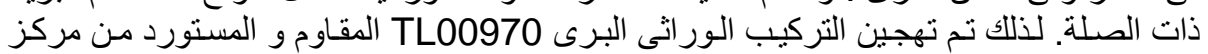

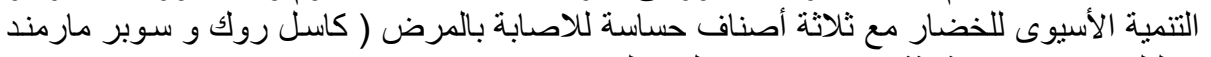

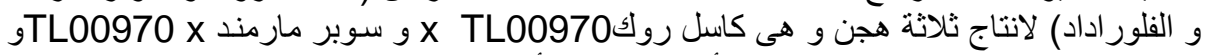

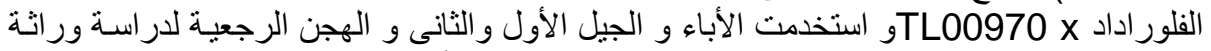

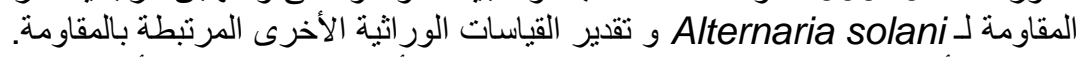

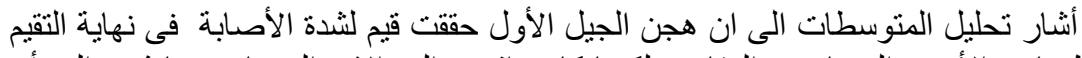

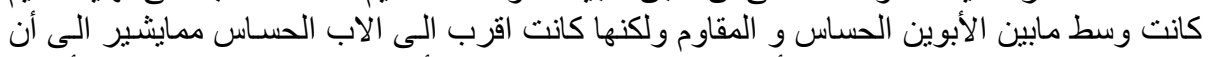

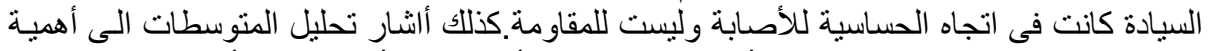

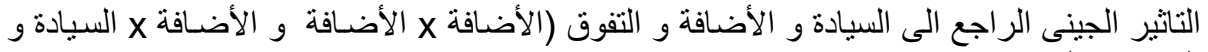

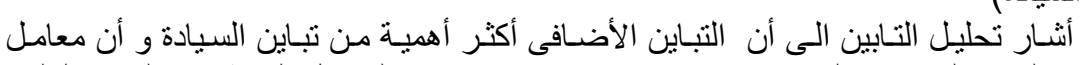
السيادة x السيادة)

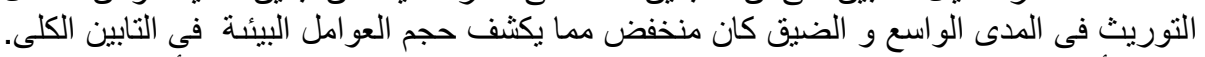

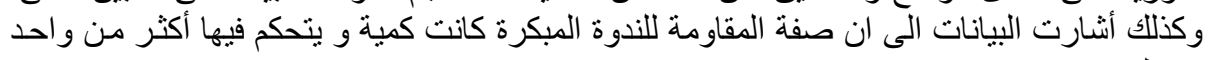

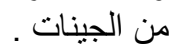

